\title{
YOUTH PARTICIPATION IN POLITICS AND COMMUNITY DEVELOPMENT PROJECTS: A STUDY OF OTA COMMUNITY OGUN NIGERIA
}

\author{
Tolulope Victoria Olatunji ${ }^{1 *}$, Moses M. Duruji ${ }^{2}$ \\ ${ }^{1}$ Ms., Covenant University, Oto, Ogun State, Nigeria, Email: tolulope.olatunjipgs@stu.cu.edu.ng \\ ${ }^{2}$ PhD. Dr., Covenant University, Oto, Ogun State, Nigeria, Email: \\ moses.duruji@covenantuniversity.edu.ng \\ ${ }^{*}$ Corresponding Author
}

\begin{abstract}
This paper aims to examine the relevance of Youth participation in the attainment of community development. The Qualitative methodology was used in conducting this research, and data was sourced from journal articles, newspapers, books, and the internet. The study shows that youth participation provides positive outcomes, from youth engagement in different forms ensuring substantial growth in the community. It further indicates that youths can take an interest in governmental or non-governmental projects that guide in empowering community development, which will reflect in the country's national development and how the government officials can make steps and policies that can be taken to upgrade youth participation. In light of the discoveries, the study suggests that Youths should position themselves as a critical instrument in realizing community development programs. The older generation should fill in as initiators to elevate youth participation to help community development; that is, the older generation should uphold the youths in shaping their peer groups to support community development.
\end{abstract}

Keywords; Community development, Community development projects Development, Youth, Youth participation.

\section{INTRODUCTION}

Community development is a process where community members are supported by agencies to identify and take collective action on issues which are important to them. Community development empowers community members and creates stronger and more connected communities. Community development is a holistic approach grounded in principles of empowerment, human rights, inclusion, social justice, self-determination and collective action (Smart, 2017). Community development is led by members of the community at every stage as they posses the knowledge and skills needed to provide the necessary growth. Growth and development are important and part of life for any real change to happen. A community cannot remain backward while the rest of the world is fast becoming a global village that breeds room for interrelations among countries.

Young people are a unique wellspring of advancements, and they have without a doubt, since the beginning, partaken, contributed and even catalyzed significant changes in political frameworks, power sharing and 
financial freedoms (Fatoyinbo, 2021). Inclusive and diverse political participation is not only a fundamental political and democratic right, but it is also essential for the development of stable and peaceful societies. To be effectively represented in political institutions, processes, and decision-making, including elections, young people must be aware of their rights and given the information and capacity to engage meaningfully at all levels (Fatoyinbo, 2021).

Various people in the community working dependently on each other to be advanced and have a more conducive life for the members of the community, while also working dependently with other communities which will then reflect on the National development of the country, it is also almost impossible to say that a country is developed or developing when communities within the country lack development and even the citizens are not adequately satisfied with the standard of living

Young people are increasingly participating in "alternative forms" of participation, such as youth activism, volunteering with in community, activism, or digital activism are all examples of activism. Climate activism is an example of a youth social movement. Movement. Youth civil society is also evolving and growing transformation.in a period of transition, moving from a system based on truly representative models that really are structured and hierarchical participation. The youths are said to be the most vibrant population of the world, the older individuals the more obsolete the thoughts and manner of carrying out will be as the world keeps on evolving, it is important to engage minds that are open to evolve as well.

The extent to which community members can mobilize their resources to solve community problems facilitates community development wherever in the world. The importance of youths in accelerating Community Development Programs has been acknowledged, particularly in small communities where they have played critical roles in education, health, environmental sanitation, mass mobilization, religious activities, and so on. Youths can be a powerful instrument for Community development programs if they participate actively and are encouraged to do so. Youth can be actively involved in Community development programs (Youth Participation in Community Development, 2021). This however, makes youth participation in community development very vital and a very part of community development process as the case maybe.

\section{STATEMENT OF THE PROBLEM}

The youth, represent a human capital resource that, if effectively engaged and deployed in the process of nation building, would drive a nation to a higher and enviable economic height in the community of nations. The youthful phase is the highest period of energy in the human life cycle for making a meaningful contribution to economic productivity, which, when directed and utilized correctly, defines the level of success obtained throughout the rest of the life cycle (Dr Joseph Ibbih \& Michael Anthony, 2015). In the light of this youth participation in politics should be practiced in any community to aid community development and ensure sustainable growth and development, over time, involving more youths in affairs that enable community development in carrying out community development projects.

There are several barriers to youth participation in Ota community development projects, including a lack of cooperation from other community members, parental influence, insufficient government assistance at the grass roots level, and inadequate recognition of youths as a formidable labor force in the community

According to (Joseph Francis \& Hlekani Muchazotida Kabiti, 2019)Youth do not really have sufficient opportunity to participate as agents of their relatively broad success in community work. Approximately 70 per cent of young people do not participate actively in community activities at all levels, as youth participation in community-based projects remains low. This reflects, on the one side, the lack of interest of young people in helping to develop. However, there is an assumption that young people have inconsistent prospects of participating in community activities. This shows clearly that obstacles to youth involvement in community development work are not well understood.

Many youths are interested in the political process but are not elected to any public office, therefore the concept of youth involvement in governance has continuously gained attention in view of the role youths play in the development of society (Umar Lawal Yusuf \& Mohammed Ali, 2014). Participation in governance and community development is considered to be essential but changing the political, cultural and economic realities have greatly affected the effective participation of young people.

\section{AIM OF RESEARCH}

The aim of the research was to investigate the degree of youth participation in development projects. To examine contribution youth, bring to the development of the community. To find out the impact of youth participation in the development of community's projects and how it reflects on political affairs. What are the 
obstacles young people in the community face that limit their ability to participate effectively in community development project? This paper would examine the interactions involving youth and other actors, such as community members, local governments, and development practitioners, and see how they have supported young people's participation in political affairs. Increasing young people's participation in community project particularly in decision-making and decision-making management, introduces them to practical experience and genuine participation.

\section{METHODOLOGY}

Data for this paper was sourced using secondary sources such as journals, newspapers, conference as well other document work done by other scholar's other documents such as government agencies and research groups of the large databases. and research by other researchers and books relating to the study. This study will be using descriptive analysis approach to analyze the data for the paper.

\section{REVIEW OF RELATED LITERATURE}

Because community development is such a diverse practice, it is difficult to establish a single history or approach. It is practiced all over the world, in both the north and the south. It can be practiced as a generalized approach, as it frequently is in the third world, that includes community member empowerment (Jossey-Bass.pyles, 2010). (Dokubo, 2021)Community development can be defined as a type of community development activity in which residents are supported by government or nongovernmental organizations in recognizing and making collective decisions on issues that are important to them. Community development is democratic in nature, and the process provides for equal participation of all members of the community, especially young, in the implementation of development projects. (Jones, 2016)Community members can become more empowered as a result of community development projects, and they will be better able to recognize and oppose conditions and structures that are leading to their disempowerment or negatively influencing their well-being. Community development is concerned with the development of a community's human qualities. This implies the realization of society evolves and the ability to control one's environment as a measure of true development, as well as an increase in material progress and a corresponding increase in the development of human capacities and social institutions, which would otherwise be superficial and temporary. (Straza, 2018) Anything dealing with people working to improve our town, whether it's social and economic needs, can be defined as Community Development. The objective is to strengthen the entire community. Community development includes city planning, landscaping, zoning, and permitting are all parts of community development. (Goel, 2014)Environmental projects together to improve human conditions for the 'well-being of their communities' is what community development creates. The community development approach focuses on establishing interactive processes that enable communities to make autonomous decisions about meeting their needs and addressing issues that are most important to them. It enhances community action rather than individual action, distinguishing it from approaches that emphasize individual well-being. (Dasimah \& Kamarul Ariff Omar, 2016)Today's town's youth population is the most numerous and active. They should be motivated to engage and join community programs and activities because they are a significant contributor to the community's well-being and the continued existence of our culture in the future. (Dezelan, 2017) Nowadays, youth are more concerned with luxury and materialistic adoption than with cultural values. If they are unable to participate in this passage of the time, the friendly and peaceful neighbourhood community cannot be lost in the future. As a result, this youth must demonstrate positive behaviour and serve as a pillar of strength, beginning with participation in their neighbourhood. (Ohana, 2020)Working to promote young people's abilities is really what youth participation entails.to possess power and influence within society. Individual or group agency Developing Youth. As a result, participation initiatives or reforms are required taking into consideration power changes and imbalances of power in the lives of young people. As a result, youth participation in democratic processes has enhanced. (Checkoway, 2011)Youth participation improves personal and social development, provides expertise for children and youth programs and services, and promotes a more democratic society, but it raises concerns about some of its most fundamental phenomena. (Matsela, 2015) Youth development is viewed as a key factor in enabling young people to live healthy, fulfilling, and productive lives as teenagers and adults. This is because they learn how to earn a living, participate in civic activities, care for others, and engage in social interactions. For example, for young people in precarious situations (sexual identity, family issues, finance distress, etc.). (Narksompong, 2015) Youth participation in decisions making can take place in a variety of settings, including the family, educational institutions, community, and business, as well as at various levels, from local to global. According to (Vakaoti, 2013)Young people in secondary or tertiary school, as well as those entering the workforce, are all included in the term "youth," as they can participate in civic life in both formal and informal settings. The participation of young people is critical to the development of meaningful 
governance systems. Young people acquire personal capacities and have the potential to make valuable contributions to society at both the practice and policy levels.

\subsection{The Role of Youth in Community Development in Nigeria}

Youth are the vital fragment of society; they are the sections for the future turn of events. Youth are social entertainers of progress and can fill in as a constrain gathering to challenge/campaigning government in characterizing their properties. It has been said that youth is by all accounts not the only future of tomorrow, but the head of today. While a large part of the consideration given to building limit (neighborhood limits is regularly engaged toward grown-up and urban association), youth are an undeniably noticeable and dynamic segment in community development improvement effort. pas. It is essential to take note of that; the young people need to identify jobs and openings which permit them to effectively show interest in the community instead of having an uninvolved job. The connection between the young people and being involved in their community development building is very key to long-term improvement in the community

(Nwaogwu \& Obele, 2017)has illustrated that young people should be completely connected and included in the effort for change and that they are to work as successful citizens. By recognizing that youths can lead, the adults can offer significant help in moving youth authority improvement from an expertise-based direction to a fundamental interest later on. (Udensi, 2013)Youth are additionally the moving power of help in any industry their interest in the business has raised the situation with numerous social orders and networks on the planet. Through sport, harmony is reinforced and social networks advanced as individuals meet up to take on interest. The degree of help and opportunity youth experience during their youth has been a connection to the probability that they will accomplish great results as youthful grown-ups. This is one of the essential ways that the young people would be setting precedents, and direction for youth follow their various capacity to flourish as independent, sound contributing individual from all areas.

\subsection{Challenges of Youths in Community Development in Nigeria}

Youth can employ regularly undiscovered assets for quick and reliable development and advancement of the community where they are allowed to thrive. Youth have the potential to mobilize themselves to see the progress of the community where the development atmosphere is positive and the society is stable. Although youth have been excluded either intentionally or unintentionally by myopic leaders especially in developing countries, however, when they are given the opportunity at various levels, they can take part effectively in the development of the society and contribute to the policy plan of the government. Young people should be completely connected and associated with development at all levels as these enable them to work as good citizens who seek to bring out the best in their country (Esene, Olumese \& Ovbiagele, 2018).

(Mohd Sani \& Shiratuddin N , 2017)Youths have been labeled as an immature group that is constantly challenging the norms of society, which has led to their being denied their social responsibility. It has been argued that media portraying the youth in a consistently negative fashion further emphasizes this contradiction. Youths are being seen as problematic and frequently involved in negative acts without being given equal credit for putting in the effort to achieve their potential. It is unfair that youths are being stereotyped because of the actions of a few people. The youths have so much to offer if given the attention they require to grow as individuals. The youths have a way of thinking ahead into the future and sometimes have to challenge old norms, because these norms and traditions may not give the community room to grow and attain a higher level of innovation and advancement. What is the point of the youths if they just continue to abide by the old norms? Without creating room for change.

\subsection{Theoretical framework}

(Benson \& Scales, 2015)Because positive youth development is a bridging field that touches multiple academic disciplines and spheres of practice, a grand theory of positive youth development necessitates the integration of multiple theoretical orientations. This section discusses three theoretical strands central to positive youth development, with a focus on the first. Human development, community organization and development, and social as well as community change. This theoretical approach encompasses everything youth participation in community development stands for. Human development is very important in every community, because if individuals fail in building their individual capacity, they might have little or no effect in the general development process of the community. Also involving in community development process can aid human development, and community organization, enhancing social changes that will bring about indepth development in various corners of the community that will reflect on the general growth of the community. Competencies, and interests in a way that allows them to reach their full potential. (Pamela Ebstyne king \& Drew Carr, 2011)Positive youth development also emphasizes the importance of youth 
participation in their own development. Youth development frequently begins with the personal pursuit of a self-identified passion, or spark. As youth pursue their passion, they continue to develop their skills in order to reach their full potential and experience fulfilment.

\section{FINDINGS}

According to (Dasimah \& Kamarul Ariff Omar, 2016) reveals that the level of youth involvement in the neighbourhood community is not encouraging, particularly in the deliberations and gatherings program; most of the youth are less interested in spending their time in social conversation and are more focused on physical activities rather than passive activities. As some of the youths are actively involved in the community's program, it was discovered that some of them were concerned and invested in the current issue and agenda on their neighbourhood developments. This goes to show that in some community's youth are being engaged in physical activities rather engaging them in discussions or activities that would directly involve them in the contribution of making strategic plans on the community development, rather relying on their youthful exorbitance only for areas that require physical strength, there is also the mental, social and emotional aspects that they can contribute to.

(Iwuchuckwu \& Ogbonna, 2015)Youth have been regarded as significant groups for community development. They play important roles such as providing leadership and selfless services in the construction of schools, townhalls, and markets. Youth, when properly channelled, can play an active role in community development.

(Umar Lawal Yusuf \& Mohammed Ali, 2014) Whatever social plan the youth are part of will continue after the adult has passed away. The only difference is that such or certain modification will occur. As a result, they are in a better position to be appropriate and long-term contributors who aid in the direction of the process. They presented large and diverse array of options, untapped resources for community development in the short and long term, it's worth noting that there is a price to pay when the youth are deprived of exposure to values, principles and education they require to make them good citizens.

As a result, any positive effort in our communities that does not involve youth is a waste of time. This is because when the old past on what has become such an effort, or better yet, when the youth are not well inculcated in the society's values and principles, they tend to build their own values and principles, which can lead to several other social vices and prevent all development efforts. Indulging the youths actively in community development would help in bringing innovative ideas and sustainability of preceding plans that are beneficial to the community.

The fact that youth participation in community development projects is linked to behavioural well-being is backed up by research (MWEI, 2016). Youth participation in community development activities and projects has been found to be influenced by factors such as increasing academic level, increasing the likelihood of college attendance, increasing community engagement, reinforcing positive social values, and setting an example. On the other hand, studies have found that other factors influence the youth's desire to participate and willingness to contribute to a greater good through participation in the implementation of certain community projects.

Participation of youth in community projects, social, political, and economic affairs place the youth at the centre of development, allowing them to exercise their right to participate in decision-making processes on issues that affect them. As a result, youth should be a part of the solution to global, national, and local issues that affect them. The youth are seen as the community's first promoters of social reconciliation; as a result, their role as agents of change and development in their respective communities enhances their competence and participation in community development projects. The community, and in particular the youths. (Joseph Francis \& Hlekani Muchazotida Kabiti, 2019). The majority of youths were also barred from speaking at community meetings. As a result, individuals have been discouraged from attending community meetings to engage in community service. The majority of the time, youth were asked to assist with adult-led activities. It was difficult for as a result of the aforementioned factors for if they are not given the opportunity, youth should be able to make a significant contribution or participate in community activities. However, some of the youths were not interested because they lacked community patriotism and philanthropic ideologies, according to the findings. This could be due to a lack of awareness about the amount of self-benefit that can be gained by participating in community development activities. Youth development practices must be introduced to such youth. This further shows the environment youths grow up in play a vital role in who they become and their interest span in wanting to be better part of the community development. While the neglect they might face may result into some of the youths being apathetic about community affairs, while the neglect might ignite a deep drive into some to change the narrative. There are youths that find themselves in 
communities where youth participation is highly encouraged it easier for such individuals to grow with the drive of wanting to contribute and be part of the development process.

There are certain challenges that have faced the youths of Ota community in participating actively in political affairs and also community development projects are put into place. These challenges need to be worked on ensure more encouragement from youths to actively participate Political socialization and culture as a pattern. The military's intrusion into politics, which has damaged democratic cultures and institutions. This has deprived youths of understanding of what ideal, proper, and civil political procedures should be. Politics has been commercialized, making it an investment, a money-making endeavour, and the one sure road to instant fortune and riches. It is no longer regarded as a stepping stone to leadership. Greed, Bribery, Corruption, and Negative Role Model Influence The political leadership structure is incorrect. The aforementioned factors, however, could be addressed and turned around by strategic groupings, political education, empowerment, and enlightenment programs. Opportunities for youths in politics abound in Nigeria. They are numerous and boundless. Some of these opportunities include leveraging and creating a unique transformation and legacy for the future based on our understanding of our past, which has led us to the present. This can be accomplished by utilizing Nigeria's youth population power. Youth can act as a catalyst for the emergence of a new Nigeria by maintaining the security of people's lives and property at all times, while adhering to the idea of the rule of law and providing equity, justice, and fair play. Using one's vigour and strength to promote rural development and integration reaps rewards. The dividends of democratic government to every corner of Nigeria, as well as the provision of basic necessities of life to all.

Generations to come will benefit from the development of new values, ideal orientation, and appropriate thinking. Become a National and International Leader by stomping their foot in the sand of time.

\section{CONCLUSION}

Community development has been proposed as an approach to addressing some of the challenges posed by larger socioeconomic and political institutions, as well as the failure of national and international policies to address them. How can the community development perspective be used in solving community issues? Because the youth had varying levels of education, they took part in the community projects in different ways. Education also encouraged youth to participate in the implementation of community development projects, according to the findings. Individual factors on youth participation in community project implementation, the study concluded that individual factors influenced youth participation in community project implementation, and youths were unaware of the importance of participating in community development project implementation. The study also found that age has an effect on how one approaches his surroundings and activities.

Opportunities for Ota community youths in politics abound, and these youths can serve as a light of new hope for Nigeria's political path. As a result, I challenge all youths, both physically and mentally, to embrace this as a challenge to make Nigeria a better place now and in the future. Based on these findings, the report suggests that Nigerians reconfirm their support to the 'Not Too Young to Run' Act. To put it another way, the government could establish Leadership and Democratic Institutes across the federation to train youth in the art of governance and prepare them for leadership. Youth will be encouraged to participate more actively in politics if they believe that their opinions matter and that the government is concerned about their political futures. It is also recommended that youth interact with themselves more on social media in order to foster capacity building and a new world order of political engagement in Nigerian politics

\section{REFERENCE LIST}

Checkoway, B. (2011). what is youth participation. Research Gate, 340-345.

Dasimah Omar \& Kamarul Ariff Omar. (2016). Youth Participation in Urban Neighbourhood Community. AMER International Conference on Quality of Life, A, (pp. 309 - 316). Indonesia.

Dezelan, T. (2017). The shrinking space for civil society and its impact on young people and their organizationa, An executive Summary. The youth participation Strategy.

Dokubo, C. (. (2021). Perceived Influence of Social Vices on Youth Participation in Community Development Projects in Port Harcourt Metropolis of River Stat. International Journal of Modern Innovations \&Knowledge (IJMIK), $122-134$. 
Dr Joseph IBBIH \& Michael ANTHONY. (2015). International Journal of Innovative Social Sciences \& Humanities Research. Youth Empowerment And Productivity: An Imperative For Economic Development In Nigeria, 86-89.

Esene, Olumese \& Ovbiagele. (2018). Developing Manpower needs inoffice technology and management for sustainable development . Nigerian Journal of Buisness Education 5(1), 237-249.

Fatoyinbo, A. (2021, September 23). Youth Participation in Politics. THE NATIONS NEWS PAPER.

Goel, K. (2014, january). Understanding Community and Community Development Defining the Concept of Community. Research gate.

Iwuchuckwu \& Ogbonna. (2015). Roles of Youth groups in rural community development in Ebonyi State . Journal of Agricultural Extention and Rural Development, 46.

Jones, I. (2016). Community development in an uncertain world: Vision, analysis and practice (2nd ed.). Australlianinstitute of family studies.

Joseph Francis \& Hlekani Muchazotida Kabiti. (2019). Impediments to Effective Youth Participation in Rural Community Development. Institute for Rural Development, University of Venda,

Jossey-Bass.pyles, L. (2010). The Community Development Context of Research. Creative community organizing. San Francisco:

Matsela, T. (2015, may 29). "Exploring Youth Participation in Community Development Organisations in the Western Cape". University of Cape Town Department of Social Development.

Mohd Sani \& Shiratuddin N . (2017). Media and Youth Participation in Social and Political Activities:. Pertinaka Journal ;SOCIAL SCIENCES \& HUMANITIES 25(s), 1-20.

Mwei, O. J. (2016). Factors Influencing Youth Participation In The Implementation of Community Development Projects: A Case of Konoin Subcounty, Bomet County, Kenya. A Research Project Report Submitted In Partial Fulfillment For The Requirements For The Award of Master of Arts Degree In Project Planning And Management of The University of Nairobi.

Narksompong, J. (2015, August 25). Youth Participation in Climate Change for Sustainable Engagement. Review of European, Comparative \& International Environmental Law, 171-181.

Nwaogwu \& Obele. (2017). Prospects of Rural youth participation in family fairing in Benue State, Nigeria; Implication for policy. International journal of Sustainable Agricuktural Research 4(3), 77-86.

Ohana, Y. (2020). whatpolitics got to do with it ? European youth work programmes and the development of critical youth citizenship. Youth.

Pamela Ebstyne king \& Drew Carr. (2011). Advances in Child Development and Behaivor. Religion, Spirituality, Positive Youth Development, and Thriving, 161-195.

Peter L Benson \& Peter Scales. (2015). Positive Youth Development ; Theory, Research ans Applications. The Theory of Positive Youth Development, 901.

Shola, A. T. (2021). Youth Political Participation, Good Governance and Social Inclusion in Nigeria:. Canadian Journal of Family and Youth, 13(2), 1-13.

Smart, J. (2017, january). What is Community Development. Austraillian iinstitute of family studies.

Straza, M. (2018, 17 December). Community Development: What It Is, Its Importance, And How To Contribute In Your City. Straza Consulting.

Udensi, L. O. (2013). youth participation in development programs. IOSR journal of Humanities and social science .13(5), 63-67.

Umar Lawal Yusuf \& Mohammed Ali. (2014). An Assessment of Youth Participation in Community Development programmes in Damaturu Local Government Area. IOSR Journal Of Humanities And Social Science (IOSR-JHSS) Volume 19, Issue 7, Ver. III (July. 2014), , PP 13-24.

Vakaoti, P. (2013, Apil 4). Young people's participation in Fiji: Merits, challenges and the way forward. Asia Pacific Viewpoint volume 54 issue 1, 77-90.

Youth Participation in Community Development. (2021, july 23). Sango Net. 